\title{
Mathematics-for-Teachers (and Students)
}

\author{
George Gadanidis \\ University of Western Ontario \\ Immaculate K. Namukasa \\ University of Western Ontario
}

\begin{abstract}
What mathematics do elementary teachers need and how might such mathematics be provided in a teacher education program? In this paper, we discuss the development of a mathematics-for-teachers component for our elementary (K-8) preservice education program. Our mathematics-for-teachers program has evolved from an elective course for 20 preservice teachers, to 440 preservice teachers working in small groups in an auditorium setting, to a fully online component. The mathematics-for-teachers component immerses preservice teachers in mathematics experiences that many of them have never had, namely, experiences where they attend deeply to mathematical relationships and have opportunities to sense the pleasure of mathematical insight. As such, our primary goal is experiential therapy (Gadanidis \& Namukasa, 2005), rather than content knowledge.
\end{abstract}

Recently, at an orientation assembly, we asked our in-coming group of 440 elementary preservice teachers how they felt about mathematics. When asked if they loved mathematics, 15-20 hands went up. When asked if they hated mathematics, a sea of hands filled the auditorium. As one elementary preservice teacher commented, "I hated math. I absolutely despised it. I still remember sitting at my desk in grade one. I was sobbing quietly, because I was struggling a bit, and I didn't finish my math on time. Thus I had to stay in at recess. Awful isn't it!” Another preservice teacher said, "Math is like an iguana. As long as it blends into its environment I don't mind it. But once I have to hold it I'm not so fond of it." Given that most elementary (K-8) teachers have to teach mathematics (in the province of Ontario), we have a responsibility to try to help them change their outlook towards the subject. We're assuming that to do this, we need to engage preservice teachers with doing mathematics, and not just learning about pedagogy. We're also assuming that engaging them with more school-like mathematics - the type of mathematics that turned them off the subject in the first place — would not be the most effective approach to take.

George Gadanidis is an Associate Professor at the University of Western Ontario. His current research interests include: mathematics-for-teachers, students as performance mathematicians, learning and teaching in Web 2.0 environments, and mathematical learning objects.

Immaculate K. Namukasa is an Assistant Professor at the University of Western Ontario. Her current research interests include: Mathematical thinking and activity; Mathematics teacher education, Non-routine problem solving and learning environments, Complexity research framework, and Critical mathematics education. Namukasa is also interested in globalization and internationalization of education. 
In this paper, (1) we discuss the evolution of our mathematics-for-teachers program, from an elective course for 20 preservice teachers, to 440 preservice teachers working in small groups in an auditorium setting, to a fully online component; (2) we define what we mean by mathematics-for-teachers and distinguish it from pedagogical content knowledge (Shulman, 1987) and specialized content knowledge (Ball, Bass, Sleep, \& Thames, 2005); and (3) we elaborate on our approach for offering mathematics-for-teachers in an online environment.

\section{Evolution of Our Mathematics-for-Teachers Program}

Most Ontario preservice teacher education programs are composed of 5 months of in-class instruction and 3 months of practicum experience. The program for elementary (K-8) teachers must prepare them to teach all subject areas and, consequently, this leaves little time for mathematics education. Accordingly, Ontario elementary preservice teachers typically receive 25-30 hours of mathematics education instruction.

Prior to 2001, our Faculty of Education mathematics education program for elementary pre-service teachers consisted of 8 two-hour workshops (with approximately 28 pre-service teachers per class) and 9 hours of lectures (approximately 440 pre-service teachers in a large auditorium). The lectures gave preservice teachers the mathematics education theory that they would then experience and discuss in a more hands-on approach in the workshops. In reviewing our program, we realized that both students and instructors valued the workshops but viewed the large lectures as not very effective. Our preference was to replace the large lectures with more small-group workshops. However, it has been difficult to do this, given monetary and logistic constraints in our Faculty of Education. Replacing the 9 lecture hours with 9 additional hours of workshops would necessitate more instructional time and space. Our Faculty of Education, whose ideal capacity is 650 preservice teachers, currently has about 850 preservice teachers (440 in K-8 and 410 in 9-12). In 2001, as a compromise solution, we replaced the large lectures with 9 online modules accompanied by a structured online discussion, where preservice teachers were organized in small discussion groups. The online content came from the lecture notes. Unlike the lectures, the online discussion offered preservice teachers the opportunity to discuss the online content in small group settings. It also gave preservice teachers a first-hand experience with online teacher education which is used with increasing frequency in the school districts where they will be employed. The online discussion was assessed which ensured participation by preservice teachers. In the first year of implementation, instructors noticed that most preservice teachers came to the workshops much better prepared in terms of having read and thought about the course readings.

In our review of our mathematics education program, we felt that we needed to add a component where pre-service teachers re-experienced mathematics. That said, there was no time available to do this in the existing structure. In 2003, one of the authors (Gadanidis, 2005) offered an elective Mathematics Course to experiment with what a mathematics-for-teachers component for elementary teachers might be like. The Mathematics Course consisted of nine 2-hour classes, and it was offered to 20 pre-service teachers. In 2004, we were able to add 8 
hours of large group lectures without giving up the online content and discussion that replaced the original lectures. That is, we in effect added 8 more hours of large group contact time to our mathematics education program. We used this time to offer a mathematics-for-teachers component, where 440 preservice teachers worked on doing and discussing mathematics in (approximately 110) small groups in an auditorium setting. Each hour-long session focused on one mathematics task. Most of the 8 mathematics tasks employed came from the elective Mathematics Course taught in the previous year. We purchased concrete materials for each session and brought them into the auditorium in large containers, and preservice teachers used paper plates to carry the materials they needed to their groups.

The auditorium-based mathematics-for-teachers component had six important characteristics. First, doing mathematics became the starting point. Most elementary teachers have narrow views of what mathematics is and what it means to do mathematics (Fosnot \& Dolk 2001; McGowen \& Davis 2001a; McGowen \& Davis 2001b). Fosnot and Dolk $(2001,159)$ suggest that "teachers need to see themselves as mathematicians," and towards this end we need to foster environments where they engage with mathematics and construct mathematical meaning. Second, the mathematics experiences for pre-service teachers were designed to be interesting and challenging enough to capture their interest and imagination and to offer the potential for mathematical insight and surprise (Gadanidis, 2004). Third, a collaborative environment was fostered, where pre-service teachers worked in small groups. Fourth, reflection was fostered. In the last 5 minutes of each session, pre-service teachers took the time to write about what they learned and what they felt during the class. Their ideas were compiled into a single document under the headings of "learned" and "felt" (anonymously), and this was distributed and briefly discussed at the beginning of the next session. This helped preservice teachers see what others learned and how they felt when doing mathematics. The learned/felt activity also served the purpose of taking attendance. Fifth, between sessions, preservice teachers had access to online interactive explorations of the activities they worked on in the auditorium. They also had access to an online discussion where they could collaborate to better understand and extend the mathematics of each activity. Last, the culminating assessment activity of the math sessions was a Math Essay. In the last workshop of the course, each preservice teacher randomly received one of the math activities explored in the mathematics-for-teachers component and had 30 minutes to 'discuss' one or two of the following: different solution approaches, mathematical extensions, what they learned from the activity, or pedagogical implications.

In 2005, we made a number of changes to the mathematics-for-teachers component. First, it was converted to a fully online component. The decision to do this was, in part, due to the challenge of running over 100 small groups in an auditorium setting and, in part, due to our desire to explore what might be possible in a fully online environment. We contemplated replacing the 8 auditorium mathematics sessions with in-class mathematics sessions, but this would necessitate more instructional time and space, making it unfeasible due to resource constraints. We also contemplated splitting into 4 smaller auditorium groups, but still faced the limitations of space and human resources. With a large 
online continuing teacher education program (approximately 5,000 online students), we have ample online learning resources, experience and interest in our Faculty of Education. Second, we reduced the number of mathematics tasks from 8 to 4, to allow for a longer sustained focus on each task. Third, the online mathematics activities were redesigned, becoming more comprehensive and incorporating video as well as text, graphics and interactive content. Third, we designed three different online Mathematics-for-Teachers courses: Measurement and Geometry, Number, and Algebra. Organizing the activities into mathematics curriculum strands allowed us to offer three distinct courses through our Continuing Teacher Education Program to inservice elementary teachers and also to parents of elementary school children. The four activities of the Algebra course were the ones that were incorporated into the mathematics-for-teachers component of our preservice program, and offered to all preservice teachers during the regular teacher education program. The Measurement and Geometry course was offered prior to their teacher education program, in August, as an optional course that they would pay for and would appear as a quarter-credit on their transcript. The course was offered to inservice as well as preservice teachers, and thirty-six teachers enrolled in this course. The Number course will be offered following their teacher education program as an optional credit. We should note that all of our activities do cut across curriculum strands, thus an activity whose main focus is Algebra may also integrate Measurement, Geometry and Number concepts. We are not confident that the strand breakdown is the best organization or the activities we use; however, the strands do correspond with the curriculum strands used in sanctioned mathematics curriculum and assessment documents in the province of Ontario and are also common to other jurisdictions.

\section{Mathematics-for-Teachers}

Two decades ago, Shulman (1987) suggested that teacher education (and research) had "a blind spot with respect to content" and the emphasis was solely "on how teachers manage classrooms, organize activities, allocate time and turns, structure assignments, ascribe praise and blame, formulate the levels of their questions, plan lessons, and judge general student understanding” (p. 8). Since then, there is growing interest among mathematics educators in what mathematical pedagogical content knowledge (MPCK) could encompass. While we think that there needs to be a dialectical relationship between content and pedagogy, the examples of MPCK that we have seen seem counterproductive as they typically define what mathematics teachers need to learn by trivializing what students need to learn. For example, MPCK tends to be defined by saying that students need to know a mathematics concept like prime or multiplication in two ways perhaps, but a teacher needs to know it in more ways. Likewise, Ball (2003) suggests that "teachers need to know the same things that we would want any educated member of our society to know, but much more (more understanding of the insides of ideas, their roots and connections, their reasons and ways of being represented)" (emphasis in original).

Many elementary school students and educated members of society, for instance, think of multiplication only in terms of repeated addition or worse still as times devoid of any deeper meaning. This is, unfortunately, the case even for people who have been successful at mathematics (Ball \& Bass, 2003). Educators 
and researchers acknowledge that this is a result of inadequate mathematics teaching. Students who have experienced rich mathematics also do think about multiplication in terms of areas or rows by columns; they can multiply fractions by fractions and decimals by decimals meaningfully. To base conceptualization of MPCK on the deficit of what students have not been taught is not very helpful. Teachers and students can both have rich mathematical understandings and attend to mathematics in deep and connected ways. The distinction made by the proponents of MPCK is not as dramatic as they suggest, and consequently does not warrant a "special" mathematics for beginning teachers as a starting point in mathematics teacher education. We believe that the starting point of the mathematics education for both students and teachers should be a sophisticated and deep exploration of mathematics of which we will give an example in the section on online mathematics.

We also do not agree with the conception of Mathematical Knowledge for Teaching (MKT) being developed by Ball et al. (2005). For example, Ball et al. give the example of the mathematical task, shown in Figure 1, and suggest that "To teach, being able to perform

307

$\underline{-168}$

Figure 1. A subtraction task this calculation is necessary. This is common content knowledge. But being able to carry out the procedure is not sufficient for teaching it." They identify four distinct domains of mathematical knowledge for teaching:

1. common content knowledge (calculating the answer to 307-168)

2. specialized content knowledge (analyzing calculation errors)

3. knowledge of students and content (identifying student thinking that might have produced such errors)

4. knowledge of teaching and content (recognizing which manipulatives would best highlight place-value features of the algorithm)

The implication seems to be that the last three domains distinguish what teachers need to know from what students need to know. But let us imagine a classroom situation where a student is solving the problem in Figure 1 on the blackboard and makes a mistake. We understand that the teacher is "analyzing the calculation error," "is identifying student thinking that might have produced the error," and is "thinking about which manipulatives (or other modeling tools) would best highlight place-value features of the algorithm" so that the student might realize the error made and be able to make sense of the formal procedure. But what are the students doing? Are they thinking? What are they thinking about? What should they be thinking about? We suggest that they should also be invited to attend to the calculation error, making conjectures about the thinking that might have produced the error, and they should be thinking about how they might model all of this so as to communicate their thinking to their peers. In fact, these types of thinking are expectations for students in many reform curricula including the Ontario mathematics curriculum for K-8 (Ontario Ministry of Education, 2005). It is not uncommon, for instance, to find a task in a textbook that asks students to analyze an error that another student has made. Namukasa (2005) argues that students should also be invited to attend to their own and to 
each other's mathematical thinking processes. This is also what the metacognitive, error, and interpretive analysis research is about.

Another problem with the example that Ball et al. use to illustrate their conception of MKT is the nature of their focus on a traditional algorithm. Their example is overly concerned with how the algorithm works and how students should learn it, rather than also focusing on other procedures for subtracting the two numbers, which would build on the personal knowledge and imagination of students and not simply on the rigid and arbitrary rules of standard algorithms. In the section that follows we share an example of the mathematics-for-teachers that we have been focusing on, the aim of which is to immerse preservice teachers in mathematics experiences that many of them have never had, namely, experiences where they attend deeply to mathematical relationships and have opportunities to sense the pleasure of mathematical insight.

\section{Mathematics-for-Teachers Online}

I felt lost at first as I struggled to remember math concepts from childhood and adolescence. I felt confused. What did a poem have to do with math? I was perplexed. Was there not only one answer to a mathematical question? I felt apprehensive. How would I discuss a mathematical concept that I did not fully understand? Then as I got into the swing of things, I felt more confident with my opinions, my answers and most importantly myself. I felt cheerful that I was experiencing math as a student and that I would hopefully be able to empathize with my future students. I felt happy that math instruction could be made to be engaging. Finally, I was giddy that I was thinking about math, actually thinking about math and not doing everything else to avoid it.

The first problem explored in the Mathematics-for-Teachers Algebra Course was Making 10. Preservice teachers are asked to find missing numbers in the equation ${ }_{-}+\ldots=10$, and then plot them as ordered pairs on a coordinate grid. Preservice teachers expressed surprise that the ordered pairs lined up. "I had the 'aha' feeling when I saw the diagonal line pattern on the graph. That was my favourite part." Pre-service teachers also noticed that the graph of ${ }_{-}{ }^{+}-10$ (that is, $\mathrm{x}+\mathrm{y}=10$ ) could be used as a visual proof of $12+-2=10$ and $\overline{11}+-1$ $=10$, since $(12,-2)$ and $(11,-1)$ line up with $(10,0),(9,1),(8,2)$ and $(7,3)$, thus satisfying the equation $\mathrm{x}+\mathrm{y}=10$. They also explored equations whose graphs were parallel and then those that were not parallel to $x+y=10$. Such mathematical connections appeared to be pleasing to pre-service teachers. "I loved the adding/graphing we did and how you could take problems and branch out ... it really makes something in my mind click.” This problem was first used with two classes of fourth grade students when one of the authors (Gadanidis, 2004) was invited to do a lesson on missing numbers (that is, solving equations like ${ }_{-}+3=7$ and $5+_{-}=12$ ). Using the above activity, students did solve a lot of missing number problems. Typical classroom activities on this topic would have students complete several unrelated missing number problems. By adding the constraint that the sum of the numbers is constant we generate a mathematical relationship among solutions. Students also explored ways of changing the 
equation $\mathrm{x}+\mathrm{y}=10$ so that the pattern of plotted ordered pairs might slope in a different direction or might be curved. Preservice teachers also used the online activity shown in Figure 2 (Gadanidis, 2005), which was based on the fourth grade activity, and which incorporated (1) a mathematical poem, (2) video annotations that pose extension problems and offer pedagogical insights, and (3) an interactive exploration of functions and their graphs. A mathematical poem is

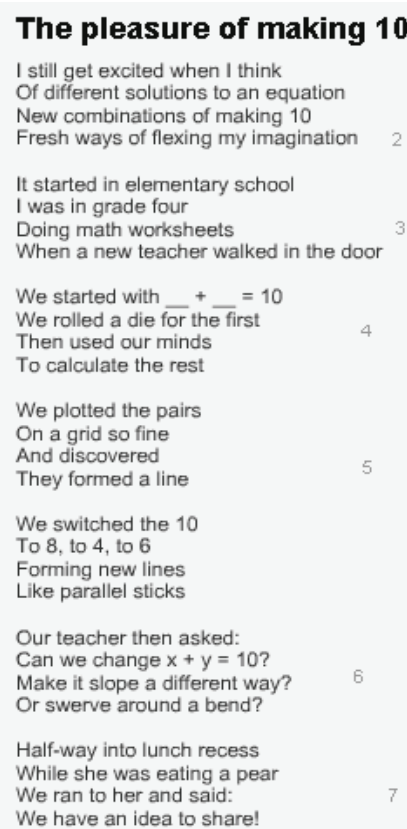

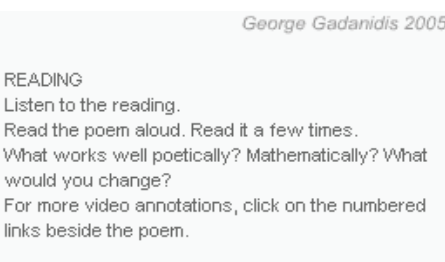

making 10

- more lines

parabola

hyperbola

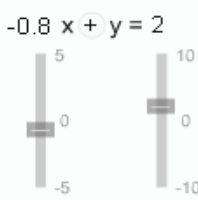

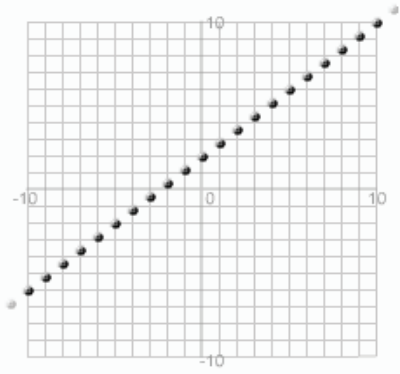

Figure 2. The Pleasure of Making 10

used as the centrepiece because, as the poet Molly Peacock (1999) suggests, poetry is screen-sized. A poem is compact enough and cohesive enough to be held in one's mind as a whole. Poetry also makes use of image and metaphor, both of which help the reader sense deeper relationships to explore (Zwicky 2003).

Such mathematical experiences do offer preservice teachers opportunities to learn mathematical concepts. However, our primary goal is not to increase their mathematical content knowledge but to provide experiential therapy (Gadanidis \& Namukasa, 2005). That is, our intention is to provide experiences that challenge and disrupt the mathematical discourse they have typically internalized through past school experiences, which is characterized by such views as: mathematics is a cold science-rather than an aesthetic, human experience (Gadanidis \& Hoogland, 2003); mathematics is about learning procedures for getting correct answers-rather than attending to and gaining insights about the complexity of mathematical ideas (Gadanidis 2004); a good teacher makes learning easy_rather than creating situations where students have to think hard (Jonassen 2000); and, teaching should start with what a child already knows and understands - rather than with what a child can imagine (Egan 1997).

We have also developed an online discussion forum (Gadanidis, 2007) whose features include (Wiki-style) editable postings, rich text postings, and a draw tool 
with drawings embedded within postings. Such online tools help enhance and enrich online mathematical communication. The drawing in Figure 3 was created by a teacher in the online discussion of the Geometry Course offered in August 2005, to illustrate how her legs are positioned to form a triangle. In the text that accompanied the drawing, the teacher discussed the three-dimensional figure she imagined being 'cut' out of space as she twirls.
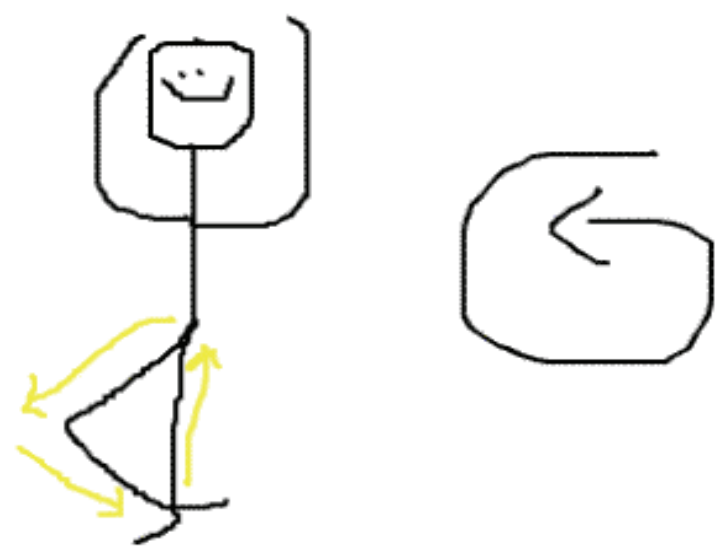

Figure 3. An online drawing

\section{Looking Ahead}

Pre-service teachers in the online Mathematics-for-Teachers: Measurement/Geometry Course (offered in the summer of 2005) overwhelmingly expressed that experiencing the Course helped change their view of mathematics and what it means to teach and learn mathematics. Similar views have been expressed by the preservice teachers in our other offerings of mathematics-forteachers. In fact, the concept of doing mathematics as a therapeutic experience came from the original mathematics-for-teacher elective described above where preservice referred to the problem solving sessions as "math therapy." Statements such as the one below were common in preservice teachers' reflections on mathematics-for-teachers and its effect on their views and beliefs.

Oh how the times have changed! In the few short months that have had the pleasure of "exploring big ideas in elementary school mathematics", my mathematical mindset has been overhauled. Now I feel empowered by math. I think mathematical experiences can change you. I was initially frustrated when I found that my classmates and myself were constantly being deprived of the solutions to mathematical situations that we were instructed to work through. The purpose of this type of an exercise soon became clear. It was the process of problem solving rather than the accuracy of the response that was being focused on. Soon I felt at ease in this pseudo-mathematical atmosphere. I started to discuss my ideas more openly with my classmates than I had initially. I had been programmed to withhold my ideas unless I was convinced that I knew the right answer, but when we knew that we were not going to be provided with the correct answer anyway, we were more open to discussing our individual strategies. 
Despite such testimonials, however, a single course experience cannot create comprehensive or permanent change in teachers' perceptions of mathematics and mathematics teaching. Neither can we assume that such an experience will significantly affect teachers' classroom practice. Teaching is also greatly affected by accepted teaching practices in the wider school community (Buzeika, 1999; Ensor, 1998) and by conflicting priorities (Skott, 1999). However, such experiential therapy (Gadanidis \& Namukasa, 2005) is an important starting point for change in teachers' perceptions and classroom practice (Gadanidis, Hoogland \& Hill, 2002a, 2002b).

As we look back on the short history of developing a mathematics course for preservice teachers, we see three patterns emerging. First, our starting point has always been to involve preservice teachers in doing mathematics - mathematics where they have to attend deeply, mathematics that offers the potential of experiencing the pleasure of mathematical insight, mathematics that engages their imagination. Second, we have never viewed the mathematics we engage our preservice teachers with as "mathematics only for teachers"-we have viewed it as good mathematics, which is also good for students, and even parents. The three Mathematics-for-Teachers courses we have developed are also now offered through our Continuing Teacher Education Program to parents, as well as inservice teachers. And, in our classroom-based research projects, they are used with students. Last, we have been willing to experiment with doing mathematics online. These patterns set the direction for our future development of mathematics-for-teachers (and students!).

\section{Acknowledgement}

This research was supported by a Standard Research Grant from the Social Sciences and Humanities Research Council of Canada.

\section{References}

Ball, D. L. (2003). Mathematics in the $21^{\text {st }}$ Century: What mathematical knowledge is needed for teaching mathematics? Secretary's Summit on Mathematics, U.S. Department of Education, February 6, 2003; Washington, D.C. Retrieved 11 October 2007, from http://www.ed.gov/rschstat/research/progs/mathscience/ball.html

Ball D. \& Bass. H. (2002). Towards a practice based theory of mathematical knowledge for teaching. Proceedings of the 2002 Annual Meeting of the Canadian Mathematics Education Study Group (p. 3-14). Kingston, Ontario: Queen's University.

Ball, D. L., Bass, H., Sleep, L., \& Thames, M. (2005). A Theory of Mathematical Knowledge for Teaching. The Fifteenth ICMI Study: The Professional Education and Development of Teachers of Mathematics, State University of Sao Paolo at Rio Claro, Brazil, 15-21 May 2005. Retrieved 22 October 2005, from http://stwww.weizmann.ac.il/G-math/ICMI/log_in.html

Buzeika, A. (1999). Teachers' doubts about invented algorithms. In O. Zaslavsky (Ed.), Proceedings of the $23^{\text {rd }}$ Conference of the International Group for the Psychology of Mathematics Education (Vol. 2, pp. 161-168). Haifa, Israel: PME.

Egan, K. (1997). The arts as the basics of education. Childhood Education 73(6), 341-345.

Ensor, P. (1998). Teachers' beliefs and the problem of the social. In A. Olivier \& K. Newstead (Eds.), Proceedings of the $22^{\text {nd }}$ Conference of the International Group for the Psychology of Mathematics Education (pp. 280-287). Stellenbosch, South Africa: PME.

Gadanidis, G. (2005). Making Ten. Retrieved 11 October 2007 from, http://publish.edu.uwo.ca/george.gadanidis/learningobjects/making10 
Gadanidis, G. (2007). Designing an Online Learning Platform from Scratch. Proceedings of EdMedia 2004, World Conference on Educational Multimedia, Hypermedia and Telecommunications, Vancouver, British Columbia, 1642-1647.

Gadanidis, G. \& Hoogland, C. (2003). The aesthetic in mathematics as story. Canadian Journal of Science, Mathematics and Technology Education, 3(4), 487-498.

Gadanidis, G., Hoogland, C., \& Hill, B. (2002a). Mathematical romance: Elementary teachers' aesthetic online experiences. Proceedings of the 26th Conference of the International Group for the Psychology of Mathematics Education, University of East Anglia, Vol. 1, 276.

Gadanidis, G., Hoogland, C., \& Hill, B. (2002b). Critical experiences for elementary mathematics teachers. Proceedings of the XXIV Annual Meeting, North American Chapter of International Group for the Psychology of Mathematics Education. Athens, GA, 1612-1615.

Gadanidis, G. \& Namukasa, I. (2005). Math therapy. The Fifteenth ICMI Study: The Professional Education and Development of Teachers of Mathematics, State University of Sao Paolo at Rio Claro, Brazil, 15-21 May 2005. Retrieved 11 October 2007, from http://stwww.weizmann.ac.il/G-math/ICMI/log_in.html

Jonassen, D. H. (2000). Computers as Mindtools for Schools. Engaging Critical Thinking (2 ${ }^{\text {nd }}$ ed.). Upper Saddle River, NJ: Merrill/Prentice-Hall.

McGowen, M. A. and Davis, G. E. (2001a). What mathematics knowledge do pre-service elementary teachers value and remember? In R. Speiser, C.A. Maher, \& C.N. Walter (Eds.), Proceedings of the XXIII Annual Meeting, North American Chapter of the International Group for the Psychology of Mathematics Education (pp. 875-884). Snowbird, UT.

McGowen, M. A. and Davis, G. E. (2001b). Changing pre-service elementary teaches' attitudes to algebra. In H. Chick, K, Stacey, J. Vincent, \& J. Vincent (Eds.), Proceedings of the $12^{\text {th }}$ ICMI Study Conference: The future of the teaching and learning of algebra (pp. 438-445). Melbourne, Australia: University of Melbourne.

Ontario Ministry of Education (2005). Mathematics, Grades 1-8. Toronto, Ontario: Queen's Printer.

Peacock, M. (1999). How to Read a Poem ... and Start a Poetry Circle. Toronto, Ontario: McClelland and Stewart.

Shulman, L. (1987). Knowledge and teaching: Foundations of the new reform. Harvard Educational Review, 57(1), 1-22.

Skott, J. (1999). The multiple motives of teaching activity and the role of the teacher's school mathematical images. In O. Zaslavsky (Ed.), Proceedings of the $23^{\text {rd }}$ Conference of the International Group for the Psychology of Mathematics Education (Vol. 4, pp. 209-216). Haifa, Israel: PME.

Zwicky, J. (2003). Wisdom \& Metaphor. Kentville, Nova Scotia: Gaspereau Press. 